\title{
LA TOPONIMIA DE LAS FUENTES EN ESPAÑA: UNA NOTA SOBRE ALGUNOS RESULTADOS DEL LAT. FONTE ${ }^{*}$
}

\author{
E. Nieto Ballester \\ Universidad Autónoma de Madrid
}

\begin{abstract}
Ay muchos lugares que su nombre empieça por fuente y la razón es porque donde no ay agua no puede aver abitación; y assi las ciudades y lugares grandes se edificaron cerca de rios, y los menores pueblos adonde huviesse fuentes (S. de Covarrubias, Tesoro de la Lengua Castellana o Española, 1611).
\end{abstract}

\section{INTRODUCCIÓN}

Es un hecho evidente y bien reconocido de todos, sobre el cual no parece que haya que insistir, que la toponimia puede proporcionarnos datos de una grandísima importancia. Estos datos conciernen, en principio, a todos los aspectos de la lengua: la fonética, la morfología, el tesoro léxico, etc. Por otro lado, está claro que la toponimia de cualquier país, región o comarca muestra a menudo la presencia del agua: el agua es, sin duda alguna, un elemento de referencia toponímica muy frecuente por razones obvias. En el caso concreto de las distintas toponimias españolas las referencias a la presencia de fuentes, manantiales, arroyos, ríos, etc., son constantes, como era esperable. En principio se puede afirmar que todas las capas que entrevemos en la historia lingüística de España muestran manifestaciones toponímicas de esta idea de fuente, manantial, arroyo, curso de agua en definitiva. Esta afirmación es acertada independientemente de la antigüedad de la capa lingüística. Así, ciñéndonos a la noción de fuente, manantial, podemos hallar ejemplos en lenguas prelatinas (indoeuropeas o no, así vasco Itu-

* Este trabajo ha sido redactado como parte del Proyecto de Investigación PB 96-0045.

RFE, LXXX, 2000, 3.-4.", págs. 395-406 
rribalzagas 'la fuente negra', Ituirgaitz 'la fuente mala, la fuente escasa', etc.), en las distintas lenguas romances españolas, en árabe (así ár. 'ayn 'fuente' en casos como Ayna, La Ina, Fuente Aiña, Alcaine, Ojailén, etc.) ${ }^{1}$.

En este todo de gran complejidad el propósito de este trabajo está referido simplemente a la palabra más atestiguada en la toponimia española (hablando en términos generales son excepción sólo las zonas menos romanizadas en lo toponímico del País Vasco y de Navarra) para la expresión de 'fuente, mamantial'. Se trata, pues, del lat. fons, fontis masculino en latín clásico, femenino posteriormente, y de su derivado fontana (aqua ${ }^{2}$. Como es sabido, las tres lenguas romances españolas actuales muestran el resultado del término latino como palabra más usual para la expresión de esta noción: cast. fuente, cat. font, gall. fonte. En un trabajo más amplio podríamos tratar sobre otros términos romances que, en una importante medida, han sustituido a los resultados de lat. fonte convertidos en algunas regiones en términos poco expresivos pára esta noción ${ }^{3}$.

\section{Dificultades DE LA INVESTIGACIÓN}

Naturalmente se han señalado a menudo manifestaciones muy abundantes de esta palabra en las distintas regiones de España, pero en lo que hace a las que hablan actualmente castellano ${ }^{4}$ soy de la opinión de que no se

\footnotetext{
1 Puede verse a este propósito E. Nieto Ballester, Diccionario breve de topónimos españoles, Madrid, Alianza, 1997, págs. 34, 71, 196-197. El caso de Ojailén (Toledo) es, a nuestro juicio, notable, toda vez que se ha producido la unión del significante romance ojo 'fuente manantial', al árabe al-'ayn. Para ojo en el sentido de 'fuente', presente también en alguno de los topónimos que tratamos en el presente artículo, véase E. Nieto Ballester, op. cit., págs. 259-260. Habría que excluir aquí tan sólo las lenguas germánicas traídas por godos, suevos, etc., cuya presencia en la toponimia española se limita tan sólo a antropónimos.

${ }^{2}$ Se señala usualmente que fontana es en castellano galicismo, pero véase M. P. Álvarez Maurín, Diplomática asturleonesa. Terminología toponímica, León, Universidad de León, 1994, pág. 217

3 Citemos aquí, tan sólo a título de ejemplo, algunas fuertes imágenes toponímicas surgidas como sustituto de fonte o de caput aquae, del tipo boca, bullón, madre, mano, etc.: Arroyo del Boquerón (Buenache de la Sierra, Cuenca), Arroyo del Boquerón del Rivero (Riolobos, Cáceres), Las Boqueras (Agoncillo, La Rioja), La Boquera (Nalda, La Rioja), Mariagua (Valsalobre, Cuenca), Maribueno (Peralveche, Guadalajara), Fuendelamadre (Cosa, Teruel), Arroyo de Lamadre (Villarejo de Medina, Guadalajara), Marazuela (Segovia), La Marota (Olmedilla de Éliz, Cuenca), Camino del Cañibulle (Campanario, Badajoz), El Bullaque (Ciudad Real), Mampodre (Asturias-León), etc.

${ }^{4}$ Entiéndase esta afirmación en su buen sentido. Naturalmente, somos conscientes de la presencia por un lado del castellano en toda España, por otro, de la pervivencia de "dialectos" como el leonés, aragonés, asturiano.
} 
ha intentado sistematizar cuidadosamente los resultados distintos del usual fuente u on-, fon- en composición ${ }^{5}$. Hasta donde sé muchos de ellos nunca han sido señalados, mientras que otros han sido reconocidos tan sólo como presentes en una región determinada, y no en un territorio más extenso. Las dificultades de esta investigación son, evidentemente, las mismas a las que se enfrenta toda investigación toponomástica. Frecuentemente los topónimos que citamos son microtopónimos poco conocidos que carecen de una documentación antigua. No pocas veces los resultados distintos del oficial han sido olvidados y han sido sustituidos por la forma regular, etc. Somos conscientes totalmente de que algunos de los ejemplos que alegamos pueden estar equivocados, pero creemos, por otra parte, que el número total de ellos no tiene demasiada importancia. La negación, verosímil, de algunos de nuestros ejemplos no puede suponer la negación del conjunto de las hipótesis ${ }^{6}$.

\section{Algunos ReSUltados poco CONOCidos del lat. FONTE EN REGIONES QUE HABLAN ACTUALMENTE CASTELlaNO. FORMAS SIN AGLUTINACIÓN DEL ARTÍCULO U OTROS ELEMENTOS}

2.1. Lat. fonte $>$ rom $^{7}$. fuante $>$ fuan-, ocasionalmente fuande: Fuambuena (apellido, Madrid, de evidente origen toponímico), La Fuansanta (Muro de Aguas, La Rioja), Fuanfría (Fanlo, Huesca), A fuande deros pun-

\footnotetext{
${ }^{5}$ Es útil recordar aquí las siguientes palabras de A. Alvar en su extraordinaria introducción a A. González Blanco, Diccionario de toponimia actual de La Rioja, Murcia, Instituto de Estudios Riojanos-Universidad de Murcia, 1987, pág. 34: “...es necesario identificar las mil variantes que presentan los latinismos fonte, rivu, ...". En lo que hace al dominio catalán, naturalmente el inmenso Onomasticon Cataloniae. Els noms de lloc $i$ noms de persona de totes les terres de llengua catalana, Barcelona, Curial $(O C)$ de J. Coromines representa una obra sin parangón; para el dominio gallego es una obra de referencia imprescindible A. Moralejo Lasso, Toponimia gallega y leonesa, Santiago de Compostela, Pico Sacro, 1977, págs. 99-143.

${ }^{6}$ La investigación se realiza, pues, en el conjunto de la España de habla actualmente sólo castellana. Se prescinde, pues, de Baleares, Cataluña, País Valenciano, Galicia y Pais Vasco. Dentro del amplio conjunto restante, por razones fáciles de entender, los datos proceden en su mayoría de aquellas provincias que disponen de un repertorio de nombres geográficos, así como de La Rioja, territorio que dispone del magnífico trabajo de A. González Blanco citado con anterioridad. Con todo, algunos ejemplos proceden del País Vasco y del País Valenciano. En el primero de los casos se trata, a nuestro juicio, de topónimos totalmente románicos. En el segundo, de zonas no catalano-parlantes. Hemos llevado a cabo también algunos muestreos en provincias que no disponen de repertorio (así León, Soria, etc.).

7 rom. indica aquí 'romance'.
} 
tarrones (Fanlo, Huesca) ${ }^{8}$, Fuente de Alifuán (Biescas, Huesca), etc. Hallamos, así pues, en estos casos un resultado /wá/ de la diptongación de /o/. Lejos de ser una evolución fonética peculiar, es un desarrollo muy conocido y extendido en España ${ }^{9}$. La sonorización de $/ \mathrm{t} / \mathrm{tras} / \mathrm{n} /$ es regular en buena parte del dominio alto-aragonés.

2.2. Lat. fonte > rom. fan-: Fanfrea (Bolea, Huesca), Fanfreda (La Fueba, Huesca), Fuente Fanfreda (Yésero, Huesca), Fuente Fanfrera (Sieste; Yebra de Basa, Huesca), Fuente Fanfría (Fiscal, Huesca) < lat. frigida 'fría', Coscujuela de Fantova (Huesca), Fantova (Graus, Huesca), Fantobal (Ayerbe, Huesca), con un segundo elemento toba < lat. tofu 'piedra caliza muy porosa y ligera, formada por la cal que llevan en disolución las aguas de ciertos manantiales', Fambiella (Sieste, Huesca) < lat. *vecla 'vieja', Fangato (Secorún, Huesca) < lat. captu 'hallado, encontrado', quizá 'encauzado', Fin de Fanz (Fanlo, Huesca), Regato Fanfón (Hornachos, Badajoz) < lat. fundu 'hondo', etc. Como en el apartado anterior se ha producido la diptongación de /o/ en /wá/, con una posterior reducción del diptongo en posición proclítica.

2.3. Lat. fonte > rom. juan (:Juan, antropónimo): Juan Amarga (Estiche, Huesca), Juan Bendita (Fanlo, Huesca), La Juambuena (Castilforte, Guadalajara), Arroyo de la Juambuena (Arandilla del Arroyo, Cuenca), Casa de Juan Caliente (Jaén, Jaén), Juan Cerrada (Cifuentes, Guadalajara), Cerro de Juan Cubierta (Cazorla, Jaén), La Juandona (Aguilar, La Rioja) 'la Fuentona', Fuente de la Juan Fría (Masegosa, Cuenca), Fuente de la Juan Fría (Cebreros, Ávila), Arroyo de la Juan Fría (Santiago de la Espada, Jaén), Juan Fría (Canena, Jaén; Moscardón, Teruel), Fuente de Juanllana (La Olmeda de Jadraque, Guadalajara), Juan Madrón (Santa Engracia, La Rioja) ${ }^{10}$, Juan de la Mano (Bienvenida, Zaragoza) ${ }^{11}$, Fuente de Juan Podrido (Valdesaz, Guadala-

${ }^{8}$ El topónimo figura así en W. D. Elcock, "Toponimia menor en el alto Aragón", Actas de la primera reunión de toponimia pirenaica, Zaragoza, CSIC, págs. 77-118, concretamente en pág. 92, aunque no en L. Ariño Rico, Repertorio de nombres geográficos, Huesca, Zaragoza, Anubar, 1980, quien lo incluye en su repertorio con la forma La fuente de los Puntarrones. La diferencia entre ambos autores es, a mi juicio, ilustrativa. Señalemos, por último, que obviamente deros está por de los, lo que no es sorprendente habida cuenta de la evolución $/ / />/ \mathbf{r} /$ entre vocales en esta zona.

${ }^{9}$ Para detalles fonéticos del hecho véase R. Menéndez Pidal, Orígenes del español. Estado lingüistico de la Península Ibérica hasta el siglo XI. Madrid, Espasa Calpe, 1986, 10.a edición, págs. 124-129; en lo que hace a La Rioja puede consultarse ahora F. González Bachiller, Aspectos fonéticos de la toponimia riojana actual, Logroño, Universidad de La Rioja, 1997, pág. 27.

${ }^{10}$ Se trata propiamente Juan Madrón de un topónimo tautológico. Para la utilización de madre y derivados en la acepción de 'manantial', véase más arriba nota 3.

${ }^{11}$ También en este caso parece Juan de la Mano un topónimo tautológico. Véase más arriba nota 3 . 
jara), Juan Podrida (Luesma, Zaragoza; Grávalos, La Rioja), Huampernal (Teberga, Asturias) < lat. perennale 'perenne, que siempre mana', cf. Fuente Peronal (Matallana, León), La Juan Podrida (Barrachina, Teruel), La Juan Pudia (Calamocha, Teruel), Los Juan Royos (Ariño, Teruel), Juan Rubia (Ibros, Jaén), La Juan Salida (Arnedillo, La Rioja), Corraliza Juan Seca (Azuara, Zaragoza), Juan Secas (Lagunilla, La Rioja), Juan Seco (Alcaudete, Jaén), Juan Somera (Torredonjimeno, Jaén), Juan Vieja (Jérica, Castellón) ${ }^{12}$, quizá Juan de Yuso (Valladolid) ${ }^{13}$, Juans (Ena, Huesca), etc. La extensión y abundancia de ejemplos muestra, a mi parecer, que no se trata tanto de alteración por etimología popular, como de un resultado puramente fonético ${ }^{14}$ : se ha producido la diptongación en /wá/ que ya hemos señalado más arriba y la posterior evolución $/ \mathrm{f} />/ \mathrm{h} /$. Entran también aquí los casos muy interesantes de Paco Otajuán (Laguarta, Huesca) < lat. opacu altafonte 'umbría fuente al$\mathrm{ta}{ }^{15}$, en donde el orden adjetivo-sustantivo parece indicar gran antigüedad $\mathrm{y}$, sobre todo, de Juances (Barbenuta, Huesca), muy notable: al margen de la evolución fonética comentada una forma *juanz de plural, con síncopa de /e/ a partir de *juantes ha sido recaracterizada con un morfema de plural -es. Se trata de un fenómeno fonético-morfológico frecuente en esta zona ${ }^{16}$.

2.4. Lat. fonte > rom. jante, jan-: Jamblán (Torres de Berretén, Zaragoza), Camino de Jantín (Nombrevilla, Zaragoza), formación diminutiva, Peña Jandeangas (Torremuña, La Rioja), etc. El desarrollo fonético combina características ya estudiadas con anterioridad: se ha producido la diptongación en /wá/, la reducción del diptongo en posición proclítica y la evolución $\operatorname{del} / \mathrm{f} />/ \mathrm{h} /$.

2.5. Lat. fonte $>$ rom. jun(te): Jun (Granada), Jumpudia (Magallón, Zaragoza), Juntipérez (Layana, Zaragoza), Junturta (Azuara, Zaragoza), < lat. fonte torta 'fuente torcida', Fuente Juntoria (La Vecilla, León), < lat. fonte

12 Véase una interpretación antroponímica en N. Nebot Calpe, Toponimia del Alto Mijares y del Alto Palancia, Castelló de la Plana, Diputació de Castelló, 1991, pág. 382.

${ }_{13}$ Así B. Sanz Alonso, Toponimia de la provincia de Valladolid. Las cuencas del Duero, Pisuerga y Esgueva, Valladolid, Universidad de Valladolid, 1997, pág. 400.

${ }^{14} \mathrm{~J}$. A. Frago García, Toponimia del campo de Borja. Estudio lexicológico, Zaragoza, Diputación provincial, 1980 , pág. 120.

${ }^{15}$ Para más detalles sobre este topónimo oscense, E. Nieto Ballester, "Paco Otajuán (Laguarta, Huesca) y Otero de Naraguantes (Fabero, León). Una nota a propósito de una imagen toponímica", Homenaje a V. Väänänen, B. García Hernández (ed.), Madrid, Ed. Clásicas, págs. 209-219.

${ }^{16}$ Sobre la caracterización general del dialecto aragonés, M. Alvar, "Aragonés", en M. Alvar (director), Manual de dialectologia hispánica. El español de España, Madrid, Ariel, 1996, págs. 263-288. Son muy útiles también M. Alvar, El habla del campo de Jaca, Salamanca, CSIC, 1948 y M. Alvar, Toponimia del alto valle del rio Aragón, Zaragoza, CSIC, 1949, con abundante bibliografia. 
aurea, cf. Hontoria de Cerrato (Palencia), etc. A mi juicio los hechos fonéticos sucedidos son los siguientes: diptongación, reducción del diptongo en posición proclítica (de manera opuesta a los casos anteriores, con eliminación del elemento más abierto de dicho diptongo) y evolución de $/ \mathrm{f} />/ \mathrm{h} /$.

2.6. Lat. fonte $>$ rom. ante / an-/am-: Ambona (apellido actual de Sigüenza, Guadalajara, sin duda de origen toponímico), Anclara (Broto, Huesca), La Ampelayo (Robres, La Rioja), Amporquera (Encinas de Esgueva, Valladolid) ${ }^{17}$ Ampudia (Palencia), Ampudia (Ajo, Cantabria), Ampudia (Alesanco; Azofra; Canillas, etc., todos en La Rioja), < lat. putida 'podrida, maloliente', Fuente del Ampuero (Guadamur, Toledo), Ampuero (Cantabria) < *pudero 'podrido', Fuente de los Antanares (Alustante, Guadalajara), Antanar (Velilla, La Rioja), Antanales (Jubera, La Rioja), donde antanar/l: fontanar/l, Antezuela (Mochales, Guadalajara), Antoria (Santa María, La Rioja), Amperosa (Tarazona, Zaragoza), etc.

La evolución fonética es clara: diptongación en /wá/, reducción del diptongo y desarticulación total de /f/ tras su paso por $/ \mathrm{h} /$.

2.7. Lat. fonte > rom. hun-/-un-: Umala (Pradoluengo, Burgos), Humayor (Trasaedo, Burgos), Fuente Umbella (Torrecilla en Cameros, La Rioja), La Hunfria (Tamames, Salamanca), Las Hunfrias (Toledo), Hungria < lat. fonte frigida (río, Guadalajara) ${ }^{18}$, Fuente de la Hurrata (El Frago, Zaragoza) < lat. rapta o bien rapida en ambos casos 'rápida veloz', Fuente Unviva (Paterna del Campo, Huelva), etc. Este desarrollo debe ser relacionado con 2.5 del que sólo se diferencia en la total desarticulación de /f/ tras su paso por $/ \mathrm{h} /$, aunque no se puede descartar que en algún caso estemos ante formas sin diptongar con cierre ulterior de $/ 0 /{ }^{19}$.

2.8. Lat. fonte > rom. en-lem-: Arroyo de la Embuena (Lacierva, Cuenca), Fuente de la Embuena (Paradinas, Segovia), Embün (Huesca), Empudia (Sorzano; Sojuela, La Rioja), El Alto Empudia (Sojuela, La Rioja), Valempudia (Leza, La Rioja), Empodrilla (Añón de Moncayo, Zaragoza). En lo fonético reseñemos que parece haberse producido diptongación en /wé/, reducción del diptongo y desarticulación total de /f/ tras su paso por $/ \mathrm{h} /$.

\footnotetext{
${ }^{17}$ Así Sanz Alonso, op. cit., pág. 202.

${ }^{18}$ El topónimo se repite exactamente en Los Hoyos de Hungría (Muro en Cameros, La Rioja). Debe ser señalado, con todo, que este topónimo conoce una variante Los Hoyos de Umbría. Cabe la posibilidad, por ende, que uno de ellos, o los dos, sean variante de Umbria.

${ }^{19}$ Esta parece ser la explicación correcta para casos como Funfria (Teberga, Asturias). Véase X. L. García Arias, Contribución a la gramática histórica de la lengua asturiana y a la caracterización etimológica de su léxico, Uviéu, Universidad de Oviedo, 1988, pág. 70.
} 
2.9. Lat. fonte > rom. in-/im-: Barranco de Val de Imaña < lat. magna 'grande' (Samper de Calanda, Teruel), La Inroya (Moyuela, Zaragoza), Fuente Im Bella (Nieva, La Rioja), La Fuente Impuria (Préjano, La Rioja) < lat. putrida. La forma es variante de la anterior $\mathbf{2 . 8}$ por diptongación tras vocal del artículo. Se puede comparar bien multitud de hechos parecidos del tipo de La Ifesa (Zaragoza) < lat. defe(n)sa 'dehesa, terreno acotado', La Iseca (Cantabria) $<$ deseca 'desecada' ${ }^{20}$, La Hiruela $<$ lat. areola 'era pequeña' etc.

2.10. Lat. fonte $>$ rom. zan-/zam-: La Fuente'l Zampornal $<$ lat. perennale (Mieres, Asturias) ${ }^{21}$, Zamprón (río, Salamanca), probablemente lat. fonte profundu, Zamudio < Zambudio (Vizcaya), Zamudio (Gimileo, La Rioja), La Zamudia (Ayamonte, Huelva), San Pedro de Zamudia (Zamora) < lat. fonte putidula ${ }^{22}$, Zancata (Castejón de Sobrarbe, Huesca), Zancada (Montalvo, La Rioja), Zancado (Sanchorreja, Ávila), Fuente del Zancado (Perales de Alfambra, Teruel) < lat. fonte capta/u 'fuente hallada, encontrada, encauzada'. La hipótesis es arriesgada en lo que hace a Zancada, en donde el resultado /d/ debe ser atribuido necesariamente al superestrato árabe-mozárabe y en donde no puede excluirse algún tipo de relación con el común zanco ${ }^{23}$. Con todo, es útil comparar Cañadas de Fuentes Cautas (La Calzada de Oropesa, Toledo), Zancorta (valle de Ayala, Álava) ${ }^{24}$ Fangato (Secorún, Huesca) ${ }^{25}$, Fuente del Cauto (Almodóvar del Campo, Ciudad Real), Fuente de la Antecada (Gárgoles de Arriba, Guadalajara, compárese Fuente Antecica, Aragoncillo, Guadalajara), Lagata (Zaragoza), Gata (Cáceres), Gata de Gorgos (Alicante), topónimos que tienen con casi absoluta seguridad lat. capta, captu como éti-

\footnotetext{
${ }^{20}$ Hipótesis de A. González Rodríguez, Diccionario de la toponimia de Cantabria, tesis doctoral inédita, Universidad de Cantabria, 1998, págs. 277-279.

${ }^{21}$ X. L. García Arias, op. cit., pág. 78.

22 Debe señalarse aquí la importancia de este punto, toda vez que el macrotopónimo vizcaíno, que, como hemos visto, reaparece en territorios tan distantes como La Rioja, Huelva o Zamora, es así románico. Véase, así, por ejemplo L. Michelena, Apellidos vascos, San Sebastián, Txertoa, 1997, 5. ${ }^{\text {a }}$ edición, pág. 134, que incluye el apellido Zambudio en su relación de apellidos vascos junto a otros "de difícil etimologia" como Areitio, Baquio, Elorrio, etc. Evidentemente las explicaciones de N. Narbarte Iraola, Diccionario de apellidos vascos, San Sebastián, Txertoa, 1997, 7. a edición, pág. 252 de Zamudio como 'desfiladeros' y de Zanbudio como 'ferreria del escampado' no pueden ser tomadas muy en serio. También se omite el topónimo riojano en la excelente monografia de F. González Bachiller citada con anterioridad.

${ }^{23}$ Evidentemente el resultado mozárabe sería Zancata, adaptada a la fonética árabe propiamente como Zancata, con posterior adaptación románica como Zancada.

${ }^{24}$ Véase I. Horch, Zur Toponymie des Valle de Mena / Castilla und des Valle de Ayala / Alava, Frankfurt am Mein, Peter Lang, 1992, pág. 398, quien recoge el topónimo. La explicación, dado el contorno vasco, no es segura, pero sí parece plausible. Es útil comparar Zamudio, también en el País Vasco.

${ }^{25}$ Es éste un ejemplo muy dudoso, toda vez que un análisis como Fang-ato, esto es, 'enfangado', es muy verosímil.
} 
mo de su segundo elemento, como muestran resultados del tipo cauto. Probablemente debamos integrar también en este grupo otros muchos ejemplos menos seguros, del tipo Zambora (Bercial, Segovia) < lat. *putra 'podrida', Zampedrero (Secorún, Huesca), Zandipueyos (El Pueyo de Jaca, Huesca), en donde pueyo es el resultado local del lat. podiu y se ha producido una sonorización de / $/$ tras nasal. Desde el punto de vista fonético señalemos que el desarrollo, sin duda extremado, conlleva la diptongación en /wá/, reducción del diptongo y equivalencia acústica entre la fricativa labiodental sorda (o incluso bilabial sorda) /f/ y la interdental fricativa sorda.

2.11. Lat. fonte $>$ rom. san-/sam-: Arroyo de Sancedo $<$ lat. fonte citu 'fuente rápida' (Vega de Espinareda, León), Samprón (León), quizá lat. fonte profund $u^{26}$. Nótese diptongación en /wá/, simplificación del diptongo en posición proclítica $\mathrm{y}$, probablemente, equivalencia acústica entre $/ \mathrm{f} / \mathrm{y} / \mathrm{s} / \mathrm{o}$ $/ \mathrm{z} /$, con posterior evolución ẹ este caso de ésta a /s/.

2.12. Lat. fonte > rom. cen-/cem-: Fuentecén (Burgos), Cenegro (Fuentecambrón, Soria), Fuencemillán < lat. fonte Aemiliani con anteposición posterior a ${ }^{*}$ Cemillán del trivial fuen (Guadalajara). El desarrollo fonético de estos ejemplos, bastante inseguros, combina fenómenos ya señalados con anterioridad: diptongación, reducción del diptongo y equivalencia acústica.

2.13. Lat. fonte > rom. sen-/sem-: Las Sensecas (Igüeña, León), Sen (apellido de Móstoles, Madrid). Se ha producido diptongación, reducción del diptongo en posición átona proclítica y equivalencia acústica.

2.14. Lat. fonte > rom. son-: Sonseca (Toledo). El detalle fonético de los hechos es dificil. Podemos partir de una forma no diptongada con equivalencia acústica $/ \mathrm{f} /: / \mathrm{z} / \mathrm{o} / \mathrm{s} /$ o bien considerar la posibilidad de diptongación y demás desarrollos en todo iguales al anterior Sensecas, con ulterior disimilación vocálica.

2.15. Lat. fonte > rom. zuen(te): Zuenzurrunera (Jaca, Huesca) ${ }^{27}$.

${ }^{26}$ Véase más arriba Zamprón, en Salamanca.

${ }^{27}$ El topónimo es, por lo demás, muy claro-zurrunera es un adjetivo en -era derivado de *zurrún, él mismo de zurrón, con cierre de /o/ final en /u/, lo que es frecuente. Parece que zurrón hace referencia aquí al ruido del agua. La imagen toponímica es muy frecuente en todas partes, expresada de maneras muy distintas: Arroyo de la Clamor (Albalate de Cinca, Huesca), Las Clamores (Lalueza, Huesca), Bramatuero (Panticosa, Huesca), Bramapán (Fanlo, Huesca), en donde -pan es lat. ponte. Puede no ser inútil comparar aquí el expresivo El $\mathrm{Zu}$ rrio del Agua (Murcia). 
2.16. Lat. fonte > rom. guante: Otero de Naraguantes (León), en donde hemos de entender lat. nigras fontes, Gobantes (Burgos), Guantes (apellido frecuente). Puede compararse bien La Güente (Santa Coloma, La Rioja). Es notable el reforzamiento articulatorio de la consonante inicial. Ciertamente el orden adjetivo + sustantivo parece mostrar una gran antigüedad. Los topónimos de este tipo son escasos, aunque no es difícil señalar algunos muy semejantes del tipo Naraval (Tineo, Asturias) < lat. nigra valle 0 Naraido (San Tirso de Abres, Asturias) < lat. nigru fagetu 'hayedo oscuro, espeso'.

Deben de entrar también aquí Guanz (Los Corrales, Huesca), que muestra un plural en $-t s>-z$ a partir de *guantes, con síncopa de /e/, y también Os guances (Sabiñánigo, Huesca), muy notable, al mostrar un plural guanz, igual al anterior, con posterior recaracterización con -es, lo que no es inusitado en este dominio lingüístico ${ }^{28}$.

2.17. Lat. fonte $>$ rom. ande-: Andecastieto (Torla, Huesca) < lat. fonte castellu, Barranco de la Andiella (El Pueyo de Fañanás, Huesca), Andina (El Franco, Asturias), Andinas (Ribadeva, Asturias), Andilla (Teruel), Santa Cruz de Andino (Burgos), Andarinos (El Grado, Huesca), Andino (apellido de Miranda de Ebro, Burgos), Los Andarrones (Bespén, Huesca), Andividria (apellido de Oña, Burgos) < lat. fonte vitrea, etc. El resultado es ante-, comentado en 2.6, con ulterior sonorización de $/ \mathrm{t} /$ tras $/ \mathbf{n} /$, lo que es frecuente.

2.18. Lat. fonte $>$ rom. ende-: Hendemaño (apellido de Medina de Pomar, Burgos), Enderrapaz (Aragüés, Huesca) < lat. fonte rapace 'fuente rápida' ${ }^{29}$. El resultado es en(te)-, comentado en $\mathbf{2 . 8}$, con posterior sonorización de $/ \mathbf{t} /$ tras nasal, igual que en $\mathbf{2 . 1 6}$.

\footnotetext{
${ }^{28}$ En lo que hace a un plural en $-z$ o $-s$ con síncopa de la vocal final cabe comparar bien otros muchos topónimos oscenses del tipo Cuatrocorz (Peralta de la Sal), Lascorz (Foradada de Toscar), Las Parez (Sieste), etc. Naturalmente el hecho aparece en otros resultados del lat. fonte: así Juans señalado más arriba, Presa de Cienfuens (Sabayés), Las Fons (Beranuy; Bisaurri; Bono), Las Fuens (Gistaín), Fuens Royas (Sahún), etc.

Dado que esta explicación de guanz-guances nos parece verosímil y dado también el hecho de que disponemos en la misma Huesca de Juan- y Juans como resultados del lat. fonte se hace necesario concluir que cabría incluir también aquí Juances (Barbenuta). Si esta explicación parece verosímil las conclusiones pueden ser de cierta importancia, pues, en lo sustancial, la explicación podría ser trasladada al conocido caso cántabro de Suances (sin explicación en A. González Rodríguez, op. cit.). En todo caso, es evidente que la comprobación de la verosimilitud de esta explicación en el caso del topónimo cántabro exige la verificación del proceso morfológico aludido en Cantabria, lo que no me consta.

${ }^{29}$ El topónimo figura en P. González Guzmán, op. cit., pág. 107, que interpreta inde y antropónimo. El topónimo, por otra parte, está ausente de L. Ariño Rico, op. cit.
} 
3. AlguNOS RESUltados POCO CONOCIDOS DEL LAT. FONTE EN REGIONES QUE HABLAN HOY CASTELLANO. TOPÓNIMOS CON AGLUTINACIÓN DEL ARTÍCULO O DE OTROS ELEMENTOS

3.1. Aglutinación de $a l$ - Este elemento al- puede ser entendido (a) bien como artículo árabe, (b) como preposición y artículo romances, sin que sea fácil precisar en cada uno de los ejemplos de cuál de las dos posibilidades se trata ${ }^{30}$. Así: Alfocea (Zaragoza), Alfoceas (Murcia), Alfosea (apellido, Orihuela, Elche, Alicante) < lat. fonte cita 'fuente rápida'. Es útil comparar aquí, sin aglutinación de al-, Foncea (La Rioja), Arroyo de la Oncea (Santa Colomba de Curueño, León). Debemos incluir también aquí Alfonseca (apellido, Madrid), Alfoseca (apellido, Callosa d'En Sarrià, Elche, Alicante), etc.

3.2. Aglutinación del artículo romance procedente de ille a an-lam-: Lanciego (Álava) ${ }^{31}$, cf. Noria de la Onciega (Urda, Toledo), Fuente Lam (Alcorlo, Guadalajara), Lanrayado (Matarrubia, Guadalajara), Landeinesa (Villalba de los Alcores, Guadalajara), que debe entenderse *l'an de Inesa, en donde Inesa es variante del usual Inés. La hipótesis puede ser corroborada por otros topónimos del tipo Arroyo de Inesa, Fuente de Inesa (Nambroca, Toledo). Es posible incluir aquí Laniturria (Ezcaray, Rioja), en donde cabría entender Lan Iturria, esto es, 'la fuente Iturria', con curiosa tautología romance-vasca. Entran aquí formas en las que se ha aglutinado tan sólo /a/ partir de un artículo la: Afanz (Broto, Huesca), Afán (apellido documentado en Madrid, Burgos, Palencia, etc.).

3.3. Aglutinación del artículo romance procedente de ille a on: Lombieja (Cabezón de Pisuerga, Valladolid), Loncedo (apellido, Villablino, León), Lon (Cantabria) ${ }^{32}$, Longil (Ampudia, Palencia), en donde gil puede ser entendido bien como nombre propio, bien como variante de ojil < ojo, en el sentido de manantial, lo que es frecuente. Puede compararse aquí Lontanar (Olba, Teruel), o bien Onraso (Peñafiel, Valladolid), bien documentado como Anraso y como Lanraso ${ }^{33}$.

\footnotetext{
${ }^{30}$ Propiamente existe incluso una tercera posibilidad en ejemplos distintos a los que aquí comentamos: lat. altu con síncopa de /o/ en sílaba interior (así A. González Rodríguez, op. cit., págs. 21, 111-112 a propósito de Aldueso y de Alcomba). Para otros ejemplos de aglutinación de al- en España véase E. Nieto Ballester, op. cit., págs. 48, 50, 52, 53, con muchos topónimos del tipo Almenar, Almonte, Almuradiel, Alpanseque, Alpedrete, todos ellos de étimo último latino.

${ }^{31}$ El topónimo alavés es, pues, a nuestro juicio, total y absolutamente románico.

${ }^{32}$ Es Lon un ejemplo muy dudoso, dado que puede entenderse bien como ${ }^{*} l u m b u>l o-$ mo $>$ *lom 'loma', con apócope.

33 Véase A. Sanz Alonso, op. cit., pág. 201.
} 
3.4. Aglutinación del artículo romance procedente de ille a fuan: Asfuanz (Fiscal, Huesca).

3.5. Aglutinación del artículo romance procedente de ille a juan: Camparajuán (Mediano, Huesca). Cf. Campafuente (Fiscal, Huesca).

3.6. Aglutinación de $n a-n o-$ al resultado fonético romance de lat. fonte: Balsa de las Nafontanas (Sallent de Gállego, Huesca), Nomparedes (Soria) 'fuente (de las) paredes', Nombrevilla (Zaragoza) 'fuente brevilla', $\mathrm{Ca}$ sa Nofuentes (Las Peñas de Riglos, Huesca), Fuente Najuán (Mosqueruela, Teruel) ${ }^{34}$, etc. No es fácil dar una explicación clara del elemento no-, na-, presente en estos topónimos. En rigor, no necesariamente habría de ser el origen el mismo en todos los casos. A nuestro juicio, las posibilidades son las siguientes: (1) aglutinación de la nasal de la preposición en; la explicación puede ser válida para casos como, Nomparedes o Nombrevilla. Partiríamos, así de *en Omparedes, *en Ombrevilla, (2) aglutinaciones sucesivas de $-a$ del artículo y de la nasal de la preposición; la explicación puede ser válida para Nafontanas y para Najuán. Así entenderíamos la/una fontana, la/una juan > l'afontana, un'afontana, posteriormente *en Afonta$n a,{ }^{*}$ en Ajuán $>*^{*}$ en Nafontana, *en Najuán. El resultado no- por último parece deberse a la atracción de la vocal /a/ a /o/ por la consonante labial siguiente, aunque no puede excluirse que se trate de un étimo distinto ${ }^{*}$ novem fontes.

\section{RECAPITULACIÓN}

Como hemos señalado hasta aquí, son muchos los resultados romances del lat. fonte en los territorios de habla actual castellana distintos del usual fuente. Naturalmente, y tal como hemos señalado más arriba, somos conscientes de que algunos o muchos de los topónimos señalados pueden recibir otras explicaciones verosímiles. Con todo, creemos que la verosimilitud de las explicaciones apuntadas puede aumentar si resumimos los topónimos señalados ahora ya no en función del resultado fonético, sino del adjetivo que acompaña en la práctica totalidad de los casos al sustantivo y que es, siempre, verosímil como acompañante de fuente o similar.

\footnotetext{
${ }^{34}$ Nótese el caso extremado de este topónimo, en el que $\mathrm{Na}$ - ha sido aglutinado a Juan que, como hemos señalado con anterioridad, es un resultado poco menos que regular de fonte. Añádase a ello la fórmula tautológica Fuente Najuán.
} 
4.1. Fuente amarga: Juan Amarga. Compárese Fuente Amarga (Huerta de Valdecarábanos, Toledo).

4.2. Fuente bella, buena: Embún, Embuena, Im bella, Fuambuena, Juambuena, Umbella.

4.3. Fuente bendita, sagrada, santa: Fuansanta, Juanbendita.

4.4. Fuente blanca, limpia, transparente: Jamblán, Andividria, Anclara.

4.5. Fuente caliente: Juan Caliente.

4.6. Fuente cerrada: Juan Cerrada. La imagen reaparece con seguridad en Güente Cerrada (Vadillos, La Rioja).

4.7. Fuente cubierta: Juan Cubierta. Para la imagen, Fuentetechada (Toledo), Fuentecha (Torre en Cameros, La Rioja), La Fuencubierta (Córdoba).

4.8. Elevada, que está en un alto: Juan Somera, Zandipueyos. Para la imagen, Fuente Somera (Bergasa, La Rioja), Fuensomera (Perales de Alfambra, Teruel), Fuente Cimera (Matallana, León).

4.9. Fuente encontrada, hallada, nacida, encauzada: Fangato (?), Fuente Antecada, Fuente del Cauto, Juan Salida, Zancada, Zancata.

4.10. Fuente fría: Fanfrea, Fanfreda, Fanfrera, Juanfria, Hungria, Hunfrías.

4.11. Fuente grande, mayor: Humayor, Hendemaño. Para la imagen, Fuenmayor (La Rioja), Sierra de la Fuenlengua (Ciudad Real), en donde -lengua es claramente lat. longa.

4.12. Fuente llana: Juan Llana. Compárese Fuenllana (Ciudad Real).

4.13. Fuente mala: Umala. Para la imagen puede ser útil el vasco Iturgaitz.

4.14. Fuente maloliente, podrida: Ampudia, Ampuero, Impuria, Empodrilla, Juan Podrida, Juan Podrido, Juan Pudia, Jumpudia, Zambora, Zamudia, Zamudio. Para la imagen, compárese Fuente Podrida (Ajamil, La Rioja).

4.15. Fuente negra: Cenero, Naraguantes.

4.16. Fuente de oro, dorada: Juntoria.

4.17. Fuente profunda: Fanfón, Samprón, Zamprón.

4.18. Fuente rápida, veloz, viva: Hurrata, Unviva. En lo que hace a la designación toponímica, Fuenterrabia (Guipúzcoa), La Rabia (Cantabria).

4.19. Fuente roja: Inroya, Juan Royos, Juan Rubia. Compárese Fuente Colorada (Villarejo, La Rioja), La Font Roja (Alcoy, Alicante).

4.20. Fuente ruidosa, que abunda en agua, por lo que ésta hace mucho ruido al fluir: Zuenzurrunera.

4.21. Fuente seca, escasa: Alfonseca, Alfoseca, Juan Seca, Juan Seco, Nombrevilla, Oncheca, Sensecas, Sonseca.

4.22. Fuente toba: Fantobal, Fantova.

4.23. Fuente vieja: Fambiella. 